\title{
LexCult
}

ARTIGOS

\section{A VALORAÇÃO PROBATÓRIA DO DEPOIMENTO ESPECIAL DE CRIANÇAS E DE ADOLESCENTES NO BRASIL E EM PORTUGAL}

\section{THE PROBATIVE VALUATION OF THE SPECIAL TESTIMONY OF CHILDREN AND ADOLESCENTS IN BRAZIL AND PORTUGAL}

\author{
Michel Canuto de Sena ${ }^{1}$ \\ Giuliano Máximo Martins, $\mathrm{Sr}^{2}$ \\ Fernando Moreira Freitas da Silva, $\mathrm{Sr}^{3}$ \\ Paulo Roberto Haidamus de Oliveira Bastos, $\mathrm{Sr}^{4}$
}

\begin{abstract}
Resumo: O objetivo do artigo é analisar a valoração probatória atribuída ao depoimento especial de crianças e de adolescentes nos ordenamentos jurídicos brasileiro e português. Com base no método de pesquisa em Direito Comparado e na revisão bibliográfica, pretende-se uma análise interdisciplinar sobre o valor de prova do depoimento especial de crianças e de adolescentes em juízo. Ao final, conclui-se que é possível a sua oitiva, desde que considerados: a maturidade do depoente, o emprego correto do método de inquirição e o uso adequado dos métodos racionais de controle da fundamentação judicial.
\end{abstract}

Palavras-chave: Valoração probatória. Depoimento especial. Criança e adolescente. Brasil. Portugal.

Abstract: The objective of the article is to analyze the probative value attributed to the special testimony of children and adolescents in the Brazilian and Portuguese legal systems. Based on the Comparative Law research method and the bibliographic review, it intends an interdisciplinary analysis on the evidential value of the special testimony of children and adolescents in court. At the end, it is concluded that it is possible its hearing, provided that: the maturity of the deponent, the correct use of the method of inquiry and the adequate use of rational methods of control of the judicial basis are considered.

\footnotetext{
1 Graduado em Direito. Especialista em Direito. Mestre. Doutorando pelo Programa de Pós-Graduação em Saúde e Desenvolvimento na Região Centro-Oeste da Universidade Federal de Mato Grosso do Sul. Professor de Direito Civil e Bioética. Membro do Instituto de Responsabilidade Civil (IBERC), Faz parte da Academia Paulista de Direito (SP).

${ }^{2}$ Mestrado em Ciências Jurídicas pela Universidade de Lisboa, Portugal (2016). Juiz de Direito do Tribunal de Justiça do Estado de Mato Grosso do Sul, Brasil.

${ }^{3}$ Mestrado em Direito Negocial pela Universidade Estadual de Londrina, Brasil (2015). Juiz de Direito do Tribunal de Justiça do Estado de Mato Grosso do Sul, Brasil.

${ }^{4}$ Doutorado em Educação (Currículo) pela Pontifícia Universidade Católica de São Paulo, Brasil (1999). MEMBRO COMISSÃO PROCESSO SELETIVO 2021 PPGSD da Universidade Federal de Mato Grosso do Sul, Brasil.
} 
Keywords: Probative valuation. Special testimony. Children and adolescents. Brazil. Portugal.

\section{INTRODUÇÃO}

Uma das intrincadas discussões que permeiam o Direito e a Psicologia é a busca pela resposta ao seguinte problema: qual a credibilidade a ser atribuída ao depoimento especial de crianças e de adolescentes no processo judicial? Ao longo da história, percebeu-se um movimento de questionamento de seu valor em razão da fantasia, da emotividade, da ausência de atenção e da fragilidade da memória. Portanto, o objetivo do presente artigo é responder ao mencionado problema de modo a apresentar critérios racionais que permitam ao magistrado valorar adequadamente a prova infantil.

Para a consecução do objetivo pretendido na pesquisa, foram utilizados o método de pesquisa em Direito Comparado, analisando os ordenamentos jurídicos brasileiro e português, a revisão bibliográfica, além de uma interface com a Psicologia, promovendo-se uma análise interdisciplinar, já que o objeto de estudo é comum às duas áreas do conhecimento.

Para tanto, desenvolve-se o artigo em cinco partes. Em um primeiro capítulo, aborda-se a prova testemunhal de crianças e de adolescentes, tanto no processo civil quanto no processo penal, bem como a diversidade de tratamento que o depoimento especial recebe em cada um deles. Em um segundo capítulo, apresenta-se o depoimento infantil como prova oral e a construção de critérios para a sua valoração, enfatizando-se a necessidade de evitar que fatores externos interfiram na qualidade da prova, além de demonstrar os métodos que permitem detectar a veracidade ou a falsidade dos depoimentos.

Em um terceiro capítulo, aborda-se a credibilidade do depoimento infantil e os métodos de inquirição adequados, devendo o magistrado estar atento a todos os detalhes inerentes à produção da prova de modo a valorá-la adequadamente. $\mathrm{Na}$ 
sequência, estuda-se a correlação entre o desenvolvimento cognitivo da criança e a relação com a norma de direito material invocada, já que, quanto maior a importância do direito material em discussão, maior será a importância da credibilidade da prova.

Por fim, no derradeiro capítulo, analisa-se o depoimento da criança como fonte única de prova, apresentando-se proposta ao magistrado para analisá-la a partir da teoria dos modelos de constatação da prova, composta pelo critério da preponderância da prova ou pelo critério da prova clara e convincente.

\section{A PROVA TESTEMUNHAL DE CRIANÇAS E DE ADOLESCENTES}

No tocante à prova testemunhal, o sistema processual civil difere do processual penal. Enquanto no processo penal qualquer pessoa pode ser testemunha de um fato (CPP, art. 202), inclusive crianças e adolescentes, que não firmarão compromisso para o ato (CPP, art. 208), no sistema processual civil os menores de 16 anos são considerados incapazes (CPC, art. 447, $\S 1^{\circ}$, III) e, como regra, estão impedidos de prestar depoimento. Todavia, sendo necessário, o magistrado poderá admitir o depoimento de crianças e de adolescentes menores de 16 anos, independentemente de compromisso, conferindo-lhe o valor que possa merecer (CPC, art. 447, $\S \S 4^{\circ}$ e $\left.5^{\circ}\right)$.

Percebe-se uma grande diferença nos sistemas de produção de prova oral. Ainda que as searas indicadas envolvam direitos fundamentais diversos em seu cerne, o sistema de produção de provas prevê diferentes comandos e uma certa contradição. Isso porque o sistema processual penal afeta diretamente um dos mais caros bens jurídicos: a liberdade de locomoção do ser humano, porém, mesmo assim, admite-se a prova oral de criança e de adolescente, ou seja, fica permitido que uma pessoa seja presa com base em um depoimento infantil, que logicamente será valorado pelo julgador. Já o sistema processual civil em que, como regra, não há afetação à liberdade de locomoção, exceto no tocante à prisão civil por dívida alimentar, o menor de 16 anos é considerado incapaz para prestar depoimento, ficando a critério do juiz, se entender necessário, permitir a sua oitiva. 
Decorrem dessa análise crítica duas fórmulas principais que aparentemente se conflitam. Ao passo que a legislação processual civil abarcou uma certa dúvida sobre o depoimento da criança e do adolescente menor de 16 anos, por não permitir seu depoimento como regra, o que dificultaria a própria valoração da prova, acabou por protegê-la de ficar à mercê de maiores constrangimentos ou questionamentos que possam ocorrer em um depoimento judicial. Nessa linha de raciocínio, tem-se que o mais adequado é mesmo tentar vislumbrar um meio termo, deixando o depoimento de crianças e de adolescentes apenas para os casos complexos e necessários, em que não existam outros meios de prova seguros e suficientes.

Outra diferença que deve ser apontada entre o processo civil e o processo penal é que esse último prevê a figura da vítima de uma infração penal. A criança ou adolescente podem ser testemunhas ou vítimas de um fato delituoso e, nessa qualidade, serão ouvidos. Logo, no processo penal, o depoimento infantil é admitido como testemunha e como vítima. O processo civil é diferente. Não existe a figura da vítima, mas apenas a de parte e de testemunha. Isso é, a criança, no processo civil, pode figurar na qualidade de parte e nessa condição ser ouvida (depoimento pessoal ou interrogatório), ou de testemunha.

A Lei $n^{\circ} 13.431 / 17$, que inovou o sistema processual ao prever um sistema próprio de tomada de depoimentos de crianças e de adolescentes vítimas ou testemunhas de violência, não fez distinção entre o processo civil e o processo penal. Ao mencionar a violência como uma base fundamental diferenciadora dos demais depoimentos tomados judicialmente, a legislação preocupou-se logicamente com a preservação de sua saúde física e mental e de seu desenvolvimento moral, intelectual e social (art. $\left.2^{\circ}\right)$.

O legislador apontou com destaque a preservação de direitos específicos de crianças e de adolescentes que estão na condição de vítimas ou de testemunhas de situações de violência, deixando bem claro que, nessa hipótese, deverão ser ouvidos por meio de escuta especializada ou depoimento especial ${ }^{5}$. E, dentre as

\footnotetext{
${ }^{5}$ Conforme se extrai dos artigos $7^{\circ}$ e $8^{\circ}$ da Lei $13.431 / 2017$, "Escuta especializada é o procedimento de entrevista sobre situação de violência com criança ou adolescente perante órgão da rede de proteção, limitado o relato estritamente ao necessário para o cumprimento de sua finalidade; Depoimento especial é o procedimento de oitiva de criança ou adolescente vítima ou testemunha de violência perante autoridade policial ou judiciária" (BRASIL, 2017).
} 
modalidades de violência, colacionou a física, a psicológica (com destaque para o bullying, a alienação parental e a exposição doméstica de violência), a sexual (abuso sexual, exploração sexual e tráfico de pessoas) e a institucional (praticada por instituição pública ou conveniada, inclusive quando gerar revitimização).

Essa última violência, denominada institucional, tem o condão de evitar que aquela criança ou aquele adolescente sofram qualquer ato de constrangimento, humilhação ou embaraço por parte de instituições públicas ou conveniadas com o Poder Público, o que se dá, inclusive, quando são questionados ou obrigados a relatar os casos de violência sofridos ou testemunhados.

Com relação à prova testemunhal infantil, o julgador deverá dizer se esse meio de prova carece de credibilidade ou se é possível decidir tomando por base suas declarações em juízo. É nesse exato momento da fundamentação que se apresenta a particular importância de dizer se a prova é válida, dentro do contexto probatório, a ponto de dela se utilizar para uma decisão final. Para isso, deverá o juiz valer-se de alguns pontos que se mostram essenciais: verificar se a criança prestou depoimento como testemunha ou como parte, avaliar se o modelo de depoimento prestado foi protetivo (como é o caso do closed circuit of television - CCTV $^{6}$ e da Câmara de Gesell $^{7}$ ), e qual foi o método de inquirição utilizado. Todos esses detalhes vão se mostrar fundamentais para o exame da credibilidade ou não do testemunho infantil.

\footnotetext{
6 "Em linhas gerais, o depoimento especial, ou a entrevista forense, como é amplamente denominado pela comunidade internacional, ocorre em formato e ambiente amigável, em local separado da sala de audiências, especialmente projetado para o acolhimento de crianças e adolescentes, que prestam seu depoimento através de um circuito fechado de televisão (CCTV, do inglês closed circuit of television). Esse ambiente, no qual também é feito o registro audiovisual da oitiva, se encontra conectado com a sala de audiências. Esse registro audiovisual segue no processo e contribui para que crianças e adolescentes não necessitem falar outras vezes sobre os fatos ocorridos" (SANTOS, 2013, p. 23).

7 "La Cámara Gesell es un espacio que está debidamente acondicionado y que permite la observación de los comportamientos sin perturbar a quienes están involucrados en casos que requieren manejo por parte de autoridades judiciales y administrativas. Concebida por el psicólogo y pediatra Arnold Gesell (1880-1961) para observar el comportamiento de niños y niñas sin que fueran perturbados por la presencia de otras personas, su estructura la constituyen dos ambientes separados por un cristal polarizado de visión unilateral, uno de observación y otro de comportamiento, y está debidamente dotada con herramientas tecnológicas para la observación y grabación" (JARAMILLO, 2019, p. 4).
} 


\section{O DEPOIMENTO INFANTIL COMO PROVA ORAL E A CONSTRUÇÃO DE CRITÉRIOS PARA SUA VALORAÇÃO}

Os diplomas processuais brasileiro e português não dispuseram expressamente sobre os métodos racionais de controle da fundamentação judicial. Todavia, ainda tímida, a jurisprudência começa a trabalhar com tais critérios, que se mostram úteis ao julgamento das demandas judiciais. ${ }^{8}$

O depoimento infantil situa-se, no campo probatório, dentre as provas orais. Pode se dar por meio de depoimento de parte ou de testemunha e, ao final, deve ser valorado pelo juiz, ou seja, analisada sua credibilidade.

O depoimento infantil não deve ser afastado de plano, exceto se o interesse da criança ou a sua condição de pessoa em desenvolvimento recomendarem o seu descarte. Assim, depois que o depoimento infantil é prestado, compete ao julgador fazer a sua avaliação, o que será realizado dentro do contexto processual.

A prova testemunhal e o depoimento de parte não se incluem dentre as provas legais prescritas pelo legislador ${ }^{9}$, de modo que devem ser analisados pelo princípio do livre convencimento do julgador, estando sujeitos, portanto, à verificação de múltiplos fatores para atestar sua credibilidade. A prova testemunhal, em si, é analisada de maneira mais intensa pelo princípio da livre convicção, de modo que esse meio de prova é o que merece, com maior destaque, uma análise crítica (CABRITA, 2015).

Destacam-se quatro fatores que podem influenciar a credibilidade de uma prova testemunhal, segundo Luís Filipe Pires de Sousa (2013). Eles estão estruturados em quatro níveis: a) fidelidade do processo mnésico; b) apreciação da imparcialidade; c) forma de prestação do depoimento; d) conteúdo do depoimento.

\footnotetext{
${ }^{8}$ PORTUGAL. Tribunal da Relação de Coimbra. Processo 1994, de 06.03.2012, Relator Teles Pereira; PORTUGAL. Tribunal da Relação de Évora. Processo 5901, de 06.12.2011, Relator António João Latas; BRASIL. Superior Tribunal de Justiça. Recurso Especial 363548/SC, de 02.05.2002, Relator Ministro Felix Fischer; BRASIL. Tribunal de Justiça do Rio Grande do Sul. Apelação 70038651477, de 27.09.2012, Relator Desembargador Umberto Guaspari Sudrack.

${ }^{9}$ Quanto ao depoimento da parte, cabe informar que, em se tratando de criança, por não possuir capacidade civil, não poderá ter efeito a confissão. Dessa forma, seu depoimento, tal qual o de uma testemunha, deverá ser cuidadosamente examinado pelo julgador quando da decisão final, de acordo com a livre convicção.
} 
Todos serão abaixo detalhados, eis que fundamentais para exame do depoimento infantil.

No primeiro nível, denominado de fidelidade do processo mnésico, preocupa-se em saber se o processo de memória da testemunha está ou não contaminado por distorções, por informação pós-evento, pelas outras testemunhas ou por perguntas sugestivas, bem como se se perdeu com o tempo ou está influenciado por questões pessoais.

Faz parte do conteúdo desse nível saber a razão de ciência da testemunha, que consiste em indicar as circunstâncias de tempo, modo e lugar em que a testemunha adquiriu o conhecimento sobre os fatos que relata. Essa razão da ciência é, em síntese, a fonte do conhecimento da testemunha. É a enunciação de como ela sabe dos fatos que the serão perguntados. Cabe frisar, a propósito, que o CPC português, no art. $516^{\circ}, n^{\circ} 1$, dispõe que a testemunha indicará a razão da ciência e quaisquer circunstâncias que possam justificar o conhecimento dos fatos, sendo que tal razão de ciência será, quando possível, especificada e fundamentada. O CPC brasileiro não prevê dispositivo semelhante, de modo que a razão de ciência, quando solicitada, fará parte do depoimento ${ }^{10}$.

Ao indicar a razão de ciência, a testemunha traz um referencial a seu testemunho. Será possível, desde logo, dizer se se trata de testemunho direto ou indireto. Isso é, será possível ao juiz e às partes esclarecimento quanto ao modo de se fazerem as perguntas. Embora não proibido, o testemunho indireto tem peso diverso do direto, até porque é mais facilmente contaminável por elementos externos.

Também quanto à fidelidade do processo mnésico, há de se fixar o que já restou determinado quanto às fases da memória: codificação, retenção e recuperação ${ }^{11}$. Na primeira fase, apenas parcela da informação vivenciada pelo sujeito passa pelo processo de codificação, dado não ser possível se atentar a tudo que está a sua volta. A formação do traço mnésico recebe influência direta de outra

${ }^{10} \mathrm{O}$ art. 457 do Código de Processo Civil brasileiro contém redação semelhante e não requer que a testemunha indique, antes do depoimento, a razão de ciência.

${ }^{11}$ A nomenclatura utilizada tem sido variada. Veja que Jorge Trindade menciona que os processos da memória englobam a capacidade de fixar, conservar, evocar e reconhecer os acontecimentos (TRINDADE, 2014). 
informação já constante da memória. Essa fase é afetada por fatores pessoais da testemunha e pelas características do evento. Encerrada a codificação inicial, a informação passa a ser retida (fase da retenção), momento em que ocorre a recodificação, com novas formações mentais para gravação daquela situação. Por fim, na última fase, o cérebro procura a informação solicitada e a recupera para fazer a respectiva comunicação.

Em todas essas fases a memória pode sofrer influências de diversas condições, de modo que compete aos instrutores da causa o cuidado para o questionamento desses fatores quando da elaboração das perguntas. Por isso, na fase de codificação, podem ser feitas perguntas de como se deu o evento, com todos os detalhes possíveis, tais como lapso temporal e luminosidade. Para saber se houve influência externa na fase da retenção, deverão ser feitas perguntas relacionadas a algum contato social externo em que a testemunha esteve exposta ou se debateu o ocorrido com outra testemunha ou terceiros. Em remate, na fase da recuperação, mostra-se de bom tom fazer questionamentos sobre o tempo decorrido entre o evento e a prestação do depoimento, sobre a forma do depoimento, o contato com quem a testemunha manteve em audiência, se foram feitas perguntas abertas ou fechadas, se foram sugestivas ou não, se houve vários depoimentos, como foi a recepção da testemunha no ambiente forense, entre outras.

Todas essas perguntas visam ao resguardo de se extrair o melhor resultado no momento da recuperação da memória e se apresenta fundamental para avaliação da fidelidade do testemunho prestado.

No segundo nível da construção de um modelo para valoração da prova testemunhal deve ser apreciada a imparcialidade do indivíduo. Aqui uma situação que deve ficar bastante clara, em se tratando de parte, é de se perceber se possui interesse na demanda, de modo que seu depoimento deverá ser analisado sob essa perspectiva. Todavia, em se tratando de testemunha, há de se avaliar sobre a existência de relações familiares, de amizade, incompatibilidade ou dependência entre as testemunhas e as partes. Cientes dessa possibilidade, as legislações processuais brasileira e portuguesa previram que a testemunha, quando de sua 
identificação em juízo, deverá informar se é parente ou inimigo das partes, se possui alguma relação de dependência ou interesse direto ou indireto na causa ${ }^{12}$.

A imparcialidade da testemunha está relacionada à ausência de um pré-juízo, preconceito, predisposição anímica ou mesmo interesse em relação às partes no processo ou ao objeto do processo (SOUSA, 2013). Como regra, sua manifestação ocorre com a prestação do testemunho sem qualquer temor, de maneira isenta, seja para favorecer ou para prejudicar uma das partes. Essa isenção há de ser cuidadosamente avaliada, dado que vários aspectos podem afetá-la, como o conhecimento de uma das partes, vizinhança, trabalho, ócio, sociedade, subordinação, amizade ou inimizade, afeto ou ódio, parentesco e interesse, de modo que o descobrimento de quaisquer dessas situações se mostra imperioso para uma análise mais apurada.

$\mathrm{Na}$ identificação de quaisquer dessas hipóteses, fica o julgador ciente de que o depoimento pode ser distorcido para favorecer uma das partes, o que pode afetar sua credibilidade. Não se pretende concluir que sempre, nessas situações, a testemunha deverá ser tida como mentirosa. Ao contrário, em ocorrendo essas relações, a testemunha poderá ser tentada a faltar com a verdade, por isso o julgador, em admitindo seu depoimento, fica ciente para verificar a sua credibilidade (CABRITA, 2015).

Uma das modalidades possíveis para se examinar a imparcialidade da testemunha está no método de inquirição, em que são feitas perguntas abertas, sem quaisquer sugestões. Nesses casos, após o breve relato livre, formulam-se perguntas específicas, o que aumenta a chance de contradição quando se trata de testemunha que apresenta uma história memorizada ${ }^{13}$.

No caso de parentesco, o legislador português faculta à testemunha a recusa a depor quando na causa sejam partes os ascendentes, os descendentes, o cônjuge, o ex-cônjuge, o sogro, o genro, o companheiro ou ex-companheiro (art.

\footnotetext{
${ }^{12}$ Ver CPC português, art. $513^{\circ}$; CPC brasileiro, art. 447, $\S 3^{\circ}$. Essas perguntas são feitas logo no início da qualificação da testemunha e permitem às partes a utilização do instituto da contradita, que é um instrumento para impugnar a credibilidade da testemunha, com o intuito de tornar seu depoimento suspeito.

${ }^{13}$ Sugere Luís Filipe Pires de Sousa que seja utilizado o método da entrevista cognitiva a essas testemunhas, com pedido para que relate o que teria visto a partir de um local diferente. Assim, como a testemunha ali não estava, dificilmente será capaz de executar essa tarefa (SOUSA, 2013).
} 
$497^{\circ}, n^{\circ} 1$, CPC português). Já a legislação processual brasileira também confere tal faculdade, ao afirmar que a testemunha não é obrigada a depor sobre fatos "que the acarretem grave dano, bem como ao seu cônjuge ou companheiro e aos seus parentes consanguíneos ou afins, em linha reta ou colateral, até o terceiro grau" (art. 448, I, CPC brasileiro).

No terceiro nível de análise da valoração da testemunha está a forma de prestação do depoimento. É o momento de se buscar examinar as linguagens verbal e não verbal utilizadas pela testemunha, que podem proporcionar elementos indicadores quanto à veracidade do relato.

Com relação aos aspectos não verbais, muitos estudos têm sido feitos sobre mudanças fisiológicas associadas à mentira e aos comportamentos que a mentira pode causar. Na primeira linha, tem sido utilizado o aparelho denominado polígrafo, dado o pressuposto de que a pessoa que mente tem alterações fisiológicas como respostas da pele, ritmo de respiração e pressão sanguínea. Ocorre que esse método pode causar falsos positivos ou negativos, seja em razão de a pessoa não ter qualquer reação no momento da prestação do depoimento (psicopata, por exemplo), seja em razão das alterações fisiológicas por nervosismo relacionadas ao comportamento não corriqueiro de prestar o depoimento (CALHEIROS, 2015).

No que se refere ao comportamento do mentiroso, diversos são os enfoques mencionados pela doutrina: os mentirosos falam em um tom de voz mais alto/agudo; fazem menos movimentos com os dedos, mãos e braços; esboçam menos movimentos do braço e da mão para modificar ou completar o que é dito verbalmente; fazem pausas maiores e têm maior latência nas respostas; demonstram menos movimentos com as pernas e pés; incorrem em mais erros de discurso em razão do esforço cognitivo ou de nervosismo (SOUSA, 2013). A isso se somam outros comportamentos, como mãos em contínuo movimento, aumento dos movimentos oculares, dilatação das pupilas, encolhimento dos ombros e evasão do contato visual. Tais constatações são deveras frágeis porque podem ocorrer com a pessoa que não está mentindo. São, na realidade, ilações sobre o que já ocorreu, 
mas não podem se tornar regra, até mesmo porque cada indivíduo reage de maneira diferente a cada situação ${ }^{14}$.

Para os indicadores verbais, alguns métodos foram criados para detectar a veracidade ou a falsidade de depoimentos, dentre eles o Statement Validity Assessment (Avaliação da Validade de Depoimentos) e o Reality Monitoring, os quais se assentam em duas perspectivas: (I) a invenção de uma história convincente sobre uma alegada experiência pessoal requer, do ponto de vista cognitivo, maiores exigências que a narração de uma história sobre um fato efetivamente vivenciado; (II) evocar uma história inventada é mais difícil que recordar um acontecimento realmente vivido (SOUSA, 2013).

Com base nessas duas constatações, vários aspectos verbais podem influenciar a credibilidade do depoimento. É possível mencionar que um relato genuíno não é absolutamente cronológico, normalmente a fala é desordenada, com digressões temporais. A indicação de considerável número de detalhes constitui, em princípio, uma indicação da credibilidade da testemunha. Descrevem-se, ainda, as complicações inesperadas e os detalhes supérfluos. São feitas correções espontâneas no relato e admite-se a falta de memória (SOUSA, 2013) ${ }^{15}$.

É de salientar, ainda, que a coerência do relato se mostra fundamental para análise de sua credibilidade. Por fim, cabe mencionar que o modelo de depoimento e o método de inquirição também influenciam esse terceiro nível de valoração do depoimento da prova testemunhal. Isso porque esses dois pontos permitem que a testemunha, notadamente a infantil, preste depoimento em um ambiente acolhedor,

\footnotetext{
14 Interessante a conclusão feita por Maria Clara Calheiros ao dizer que "[...]a única certeza que parece rodear estes mecanismos é a da sua falibilidade. Realmente, conclui-se que apenas o 'nariz de Pinóquio' conseguiu, até hoje, demonstrar absoluta infalibilidade [...]” (CALHEIROS, 2015, p. 161). Na mesma linha, destaca-se Jordi Nieva Fenoll (2012, p. 121-141).

${ }^{15} \mathrm{~A}$ jurisprudência, a propósito, já tem se atentado para esses detalhes: "O depoimento oral de uma testemunha é formado por um complexo de situações e factos em que sobressai o seu porte, as suas reações imediatas, o sentido dado à palavra e à frase, o contexto em que é prestado, o ambiente gerado em torno da testemunha e a forma como é feita a pergunta e surge a resposta" (PORTUGAL. Tribunal da Relação do Porto, Apelação 9951197, de 24.01.2000, Relator Pinto Ferreira); "(...) a atividade judicatória na valoração dos depoimentos tem de atender a uma multiplicidade de fatores que tem a ver, designadamente, com as garantias de imparcialidade, as razões de ciência, a espontaneidade dos depoimentos, a seriedade, o raciocínio, as lacunas, as hesitações, a linguagem, o tom de voz, o comportamento, as coincidências, as contradições, a linguagem gestual, etc." (PORTUGAL. Tribunal da Relação do Porto, Apelação 0820528, de 01.04.2008, Relator Guerra Banha).
} 
sem contato com as partes, e por meio de um método que permita um relato diferenciado, apto a ser valorado de maneira mais adequada.

No quarto nível de valoração está o conteúdo do depoimento, ocasião em que deve ser observada a segurança e a assertividade da testemunha, a sua autenticidade consubstanciada no esforço em reproduzir fielmente as recordações, a sua perceptibilidade traduzida em um discurso claro, escorreito e sem ambiguidades, além da verossimilhança, baseada nas máximas de experiência.

Também devem ser destacados o rigor e a precisão do relato, sendo que, se estiverem lastreados em outro elemento de prova, acabam por fortalecer a credibilidade do seu depoimento. Isso significa que, se a prova testemunhal for corroborada por outros meios de prova, que se articulam e se conjugam entre si, o depoimento acaba sendo mais crível (SOUSA, 2013).

Ocorre que essa conjugação com outros elementos de prova não deve ocorrer de maneira quantitativa, mas qualitativa. Isso porque não basta a somatória de provas em um determinado sentido. Há de se examinar se a prova está conjugada coerentemente naquele sentido e considerar que a memória do ser humano não é infalível, de modo que poderá haver discrepâncias absolutamente justificáveis (CABRITA, 2015).

Esses são os níveis que se mostram necessários para valoração da prova testemunhal. Por certo que eles devem ser analisados dentro do contexto processual, com o exame individual da prova testemunhal, do seu conteúdo e do modo de prestação, bem como por meio da comparação do conteúdo daquele depoimento com as demais provas produzidas no processo. No tocante ao depoimento infantil essa análise ganha maior relevância em razão da sua peculiar condição de pessoa em desenvolvimento.

\section{A CREDIBILIDADE DA CRIANÇA E OS MÉTODOS DE INQUIRIÇÃO ADEQUADOS}

No contexto da prova testemunhal infantil, sua valoração tem se alterado no decorrer da história. Enquanto em algumas épocas os testemunhos infantis foram 
considerados puros e inocentes, em outras foram considerados potencialmente perigosos, por sua baixa capacidade intelectual e suscetibilidade de manipulação por um adulto. São muito citados os testemunhos infantis levados a cabo em Salem, no final do século XVII, em que várias pessoas foram condenadas em razão do testemunho de crianças que teriam sido vítimas ou testemunhas de bruxaria. Nessa época, os testemunhos das crianças ganharam destacada relevância. Somente a partir dos estudos de psicologia científica, a partir do final do século XIX e início do século $X X$, é que a memória das crianças foi colocada em dúvida, dada a incapacidade de distinguir entre a realidade e a fantasia (MANZANERO, 2010).

Com base nesses estudos de retirada da credibilidade do depoimento infantil é que considerável parcela da doutrina tem colocado esse depoimento como perigoso para a busca da verdade processual (SANTOS, 1972) ${ }^{16}$. Os argumentos utilizados para retirar o crédito de um testemunho de criança estão na imprecisa percepção do mundo exterior e de seus detalhes, a fértil imaginação (fantasia), a emotividade, a imperfeição no processo de atenção e a frágil memória. Além disso, citam ser tomado de egocentrismo; de ausência de noção de espaço e de tempo; de elevada sugestionabilidade, o que compromete a veracidade dos fatos que estão a ser inquiridos.

Para a escorreita valoração da prova testemunhal, os modelos e os métodos de inquirição servirão como fundamentais a fortalecerem os critérios mencionados em que se deve basear o juiz quando da prolação da decisão judicial.

Os modelos de inquirição estão relacionados ao ambiente em que a criança vai prestar o seu depoimento, tais como o closed circuit of television - CCTV e a Câmara de Gesell, anteriormente conceituados, que objetivam a proteção da criança como pessoa em condição especial de desenvolvimento, de modo que, por meio deles, a criança não mantenha contato direto com as partes, é recebida de maneira diferenciada nos tribunais e não fica sujeita a perguntas vexatórias ou constrangedoras das partes, situações que permitem a redução da vitimização secundária.

16 Ver também: ALTAVILLA, 2007; MALATESTA, 2005; PESSOA, 2006; RASSIER, [S/D]; BATTISTELLI, 1963. 
Se o modelo de inquirição adotado reduz a possibilidade de estresse por parte da criança quando da tomada do depoimento, nomeadamente por não manter contato com qualquer das partes, por certo que as consequências emocionais daquele ato serão menores, o que vai influenciar a prestação do depoimento ou das declarações.

A conexão que se faz entre os sentimentos de emoção e temor com a memória tem duas conotações principais. Uma está relacionada aos casos graves, em que a criança acaba por calar a verdade ou retratar-se dos fatos anteriores, denominada síndrome do segredo, e outra no sentido de se criar um ambiente propício para a criança reviver aqueles fatos pretéritos, procurando o mesmo sentimento experimentado, o que facilita a recuperação da memória.

$\mathrm{Na}$ primeira situação, mais especificamente para as situações em que a criança é vítima de um fato grave, normalmente de cunho sexual, tem sido destacado o secretismo daquela situação, ainda mais quando ocorrem em situação intrafamiliar. A síndrome do segredo é algo construído pelo agressor para a não divulgação daquela situação de violência por meio de ameaças (FURNISS, 1993).

Ocorre que fatores de ordem externa e interna fortalecem a manutenção daquele segredo. Dentre os fatores externos que influenciam essa síndrome estão a inexistência de prova material do delito, restando apenas a prova oral, que fica completamente comprometida pela ameaça. A isso soma-se o receio de a criança não ser acreditada por seus familiares, pelos órgãos públicos e pelo sistema de justiça, e a ansiedade em relação às consequências da revelação, com transferência à criança da culpa por eventual punição posterior. Ora, fica nítido, portanto, que o fator emocional é fundamental para a escorreita elucidação dos fatos, dado que, enquanto a criança estiver em situação de temor, o segredo, ou seja, a verdade, dificilmente será revelada.

A hipótese da criança vítima de um crime é um exemplo drástico no sentido de que o fator emocional influencia a obtenção de um depoimento verdadeiro. Os modelos protetivos de tomada de depoimento, como os citados CCTV e a Câmara de Gesell, podem, inclusive, não abrir espaço para a revelação do segredo, dado 
que sua estabilidade emocional, antes da audiência, e a ansiedade do que poderá ocorrer posteriormente afetam aquele momento.

O modelo protetivo permite um relato mais espontâneo, sem o contato com as partes e sem o recebimento de perguntas vexatórias ou constrangedoras. Lógico que outros fatores pessoais e familiares podem auxiliar nessa ocasião, tais como a estabilidade emocional da criança, a sua autoconfiança e a atuação efetiva de outros órgãos protetivos para que não mantenha contato com o infrator. Desse modo, aliada à técnica de inquirição, o modelo de depoimento protetivo permite melhor capacidade de recordar, de resistência à sugestão e proporciona um depoimento mais crível ${ }^{17}$.

O outro viés da redução do estresse no momento da prestação do depoimento está relacionado com a permissão de que a criança reviva as emoções, normalmente negativas, quando da recordação dos fatos. Vários foram os estudos realizados sobre o tema, chegando-se à conclusão de que as emoções negativas podem possibilitar recordação mais verdadeira, porém também podem produzir falsas memórias (STEIN; PERGHER; FEIX, 2009). Disso resulta que, quanto mais elevada a intensidade emocional da criança quando da ocorrência dos fatos, maior a chance de ela se recordar de maneira mais precisa dos fatos (MANZANERO, 2010).

A memória tem melhor recuperação a partir do momento em que as emoções experimentadas são novamente vivenciadas com o seu relato. Essa nova perspectiva de resgate das emoções e, portanto, dos fatos, dá-se com mais facilidade em um ambiente adequado, sem a participação das partes e com redução da vitimização secundária.

Resulta lógico que um ambiente equilibrado, distante das partes, que é o modelo protetivo (CCTV e Câmara de Gesell), constitui um fator que permite à criança a revelação do segredo, desde que aliada a outras condicionantes, e o

\footnotetext{
${ }^{17}$ Calha trazer a conclusão do estudo de Carlos Casimiro Nunes no sentido de que a colheita do testemunho "[...] de crianças e jovens, neste contexto, deveria ser realizada, em locais adaptados para o efeito, por profissionais com competência na área (psicologia e abuso sexual) pois é reconhecido que tal circunstância permite uma melhor capacidade de recorder, de resistência à sugestão e proporciona um testemunho mais credível dos factos, para além de reduzir o risco de dano secundário." (NUNES, 2005, p. 261-305).
} 
reavivamento das emoções que lhe marcaram os fatos, abrindo espaço para a narrativa de ocorrências mais próximas à realidade.

Ocorre que o modelo de depoimento deve estar aliado a um modelo de inquirição adequado para se extrair a melhor qualidade de informação possível. Isso porque o formato das perguntas, o comportamento do entrevistador e o fortalecimento da confiança da criança, ocorrentes nos modelos de inquirição mencionados, são marcos diferenciadores do modelo tradicional de tomada de depoimento em audiência e auxiliam de maneira decisiva na obtenção de informações fidedignas.

De uma maneira geral, todos os protocolos explanados sublinham a necessidade de uma recepção adequada da criança, com o estabelecimento de um rapport respeitoso e com conversas neutras. Ainda nessa fase, tem-se a explanação à criança da maneira como se dará o depoimento. Por fim, todos preconizam a necessidade de se fazerem perguntas abertas, sem sugerir ou introduzir na criança um elemento fático importante. Somente quando necessário as perguntas devem ser mais focalizadas, sem sugerir, contudo, uma situação específica, ou seja, abrindo margem à criança para que responda com suas próprias palavras sobre o acontecido.

Ademais, os protocolos examinados se preocupam com a capacitação do entrevistador, cujo conhecimento é profundo no que tange às fases do desenvolvimento das crianças. O entrevistador, ciente da idade da criança e de seu grau de maturidade, pode perceber o ambiente sociocultural em que ela vive e poderá fazer as perguntas da melhor maneira possível. Essa constatação por parte do entrevistador advém de um rapport bem-feito, em que a criança é estimulada, por meio de conversas neutras, a se comunicar abertamente.

Ao se partir da premissa de que as perguntas não são sugestionáveis e que a criança pode relatar os acontecimentos de maneira livre, dela se poderão extrair os melhores resultados ou, ao menos, perceber seu intento em não esclarecer a verdade.

A utilização de técnicas que se valem dos conhecimentos da psicologia do testemunho permite a obtenção de informações mais fidedignas, a despeito da 
possível existência de erros e distorções. A criança, com a utilização desses métodos, acaba por fornecer informações relevantes em seu depoimento. Apesar de ainda restar muito a ser feito no campo dos estudos científicos dessas técnicas e de não existir um método infalível, esses métodos de inquirição da psicologia dão subsídios para os operadores do direito, dado que suas bases são sólidas e conferem maiores chances de alcance da verdade (STEIN; PERGHER; FEIX, 2009) 18 .

Assim, a utilização dos métodos de depoimento e de inquirição busca trazer o equilíbrio entre a busca da verdade e a efetiva proteção da criança (BALBINOTTI, 2009), de modo que, quando da valoração da prova, convém deixar evidenciada a utilização desses métodos.

\section{O DESENVOLVIMENTO COGNITIVO DA CRIANÇA E A CONTEXTUALIZAÇÃO DA PROVA ORAL COM A NORMA DE DIREITO MATERIAL INVOCADA}

Para além dos modelos e métodos de inquirição, é fundamental considerar o desenvolvimento cognitivo da criança e a contextualização do depoimento infantil com os demais meios de prova produzidos, além de relacioná-los com o direito material invocado na demanda para se definir o modelo de constatação aplicável ao caso.

Com relação ao desenvolvimento cognitivo da criança, algumas considerações preliminares devem ser destacadas. Como já dito anteriormente, o fator etário se mostra como um critério geral para verificação da maneira como a criança pode fazer um relato de acontecimentos por ela vivenciado. Ainda que casos particulares possam ser individualmente analisados, como regra, e, seguindo-se a orientação da Psicologia, as crianças de tenra idade não estão capacitadas para prestação de depoimento infantil, isso porque seu linguajar sequer está desenvolvido o suficiente para a narrativa fática.

Por isso, as crianças até os dois anos de idade não possuem capacidade cognitiva mínima para relatar um fato. A linguagem está em fase de aprendizado,

\footnotetext{
${ }^{18}$ Ver também: CÉZAR, 2007; WELTER, 2010.
} 
sua relação com o mundo exterior é restrita e a sua capacidade de entendimento é baixa, dado que seu pensamento é simbólico, com uso de representações simbólicas de eventos, de objetos e de apresentação de sinais de raciocínio, além da compreensão da permanência de objetos (PIAGET, 1971).

Maior desenvolvimento da linguagem e utilização de símbolos de maneira mais ampla são características da próxima etapa do desenvolvimento infantil, que vai dos dois até os sete ou oito anos de idade. Diante disso, a criança é capaz de pensar por meio de representações e atribuir significados à realidade (SADOK; SADOK, 2007). Entretanto, a despeito da evolução do pensamento pela linguagem, característica marcante dessa fase é o egocentrismo, uma vez que a criança não concebe uma realidade da qual não faça parte. Desse modo, apesar da capacidade de atuar de forma lógica e coerente, apresenta um entendimento desequilibrado da realidade (TERRA, 2020). Por essa razão, o depoimento de criança, nessa fase, ainda não se apresenta recomendado, devendo ser redobrado o cuidado por parte do julgador, caso proceda a ele. Isso porque, apesar de a memória da criança estar relacionada a fatos por ela vivenciados, na esteira do que defendido por Vygotsky, na visão histórico-social, ainda existe uma confusão entre realidade e ficção (PASQUALINI, 2020).

A partir dos sete ou oito anos, a capacidade de estabelecer relações, de coordenar pontos de vista e de integrá-los de modo lógico permite que seu depoimento seja prestado de maneira menos problemática. A recuperação da memória, nessa fase, apresenta-se de forma lógica, apesar de ainda conter imaturidade. Eventual depoimento de criança que esteja nessa faixa etária há de ser considerado pelo juiz dentro dessas perspectivas, dado que somente assim ele poderá ser contextualizado com as demais provas dos autos.

Diante do grau cognitivo de uma criança de sete ou oito anos de idade, entende-se possível que um depoimento seja tomado em um processo judicial e que o respectivo relato seja considerado pelo julgador. Apesar de essa faixa etária permitir um depoimento, o juiz não pode deixar de considerar o depoimento dentro do aspecto de uma pessoa que está em especial condição de desenvolvimento. 
Quando a criança ingressa na quarta etapa do desenvolvimento infantil, o que se dá a partir dos onze ou doze anos, seu raciocínio engloba situações de abstração e sua memória é capaz de reproduzir aqueles elementos que mais the marcaram a atenção, de maneira bastante semelhante à de um adulto. Dos ensinamentos da Psicologia, percebe-se que a cognição do indivíduo vai se desenvolvendo à medida que sua idade vai aumentando, ou seja, o contato com o mundo exterior e sua subjetiva compreensão vão se aprofundando no plano do relacionamento. Diante dessa constatação, tem-se que o depoimento de uma criança a partir dessa idade se mostra perfeitamente possível. Sua valoração, tal qual uma testemunha adulta, contudo, depende da contextualização da prova oral com outras constantes no processo.

Resumidamente, a partir dos sete ou oito anos de idade, critério este utilizado que não encontra limites fixos, o depoimento da criança pode se mostrar útil ao processo. Sua capacidade cognitiva permite que se recorde e reproduza fatos por ela vivenciados, de modo que a entrevista por um modelo protetivo e por um método narrativo de inquirição dará instrumentos necessários ao juiz para julgamento da causa (FENOLL, 2012).

Nada impede, contudo, que, se houver dúvidas sobre a higidez mental da criança e da sua maturidade, seja realizado um laudo pericial psicológico para determinar o grau de cognição da criança naquele momento. A realização desse laudo pericial pode vir a reforçar ou diminuir a intensidade da prova no momento do depoimento judicial. Trata-se de uma cautela para as partes e para o juiz, o que permite uma mais acurada análise do conteúdo do documento (POIARES, 2004).

Ocorre que, para uma valoração da prova mais adequada, não basta a indicação de uma idade mínima ou a utilização de modelos ou métodos de inquirição, é crucial ainda que o depoimento da criança tenha algumas características que Ihe deem credibilidade e seja devidamente contextualizado com as demais provas dos autos.

Um dos fatores de credibilidade do depoimento da criança é a coerência do relato. Uma narrativa sem contradições ou falhas graves torna mais crível o relato do ponto de vista do juiz. Não se deve esperar, contudo, assertivas perfeitas, sem 
pequenas falhas ou contradições. Como já dito, se a memória de um adulto é falha e permite pequenos deslizes, o mesmo pode acontecer com a de uma criança. Assim, a coerência que se espera diz respeito ao fato principal a ser arguido e já considera as possíveis falhas da memória. Diante disso, tem-se que um relato preparado e decorado por uma criança pode ser facilmente descoberto com a utilização de um dos métodos narrativos de entrevista (FENOLL, 2012).

Outro ponto a ser considerado na narrativa da criança está relacionado com o contexto do seu depoimento, com seu grau cognitivo, sua condição e seu interesse no processo e as demais provas produzidas. O depoimento de uma criança no processo deve estar relacionado ao seu interesse na causa, conforme interpretação da Convenção sobre os Direitos da Criança. Assim, logo depois de tomar conhecimento de seu grau cognitivo, há de se saber qual o interesse da criança na demanda judicial. Somente assim será possível fazer uma contextualização adequada de seu depoimento.

Não bastasse, a prova oral através das declarações ou depoimentos de uma criança há de ser analisada com as demais provas dos autos. Uma prova pericial ou mesmo outra prova testemunhal que corrobora o depoimento infantil tornam esse meio de prova muito mais crível. Da mesma forma, na existência de uma contradição com outros meios de prova, há de se atentar às condições cognitivas e de interesse da criança no processo, pois somente assim se poderá extrair alguma possível justificação daquela conduta (HERMIDA, 2010).

A partir do momento em que a prova oral infantil encontra apoio em outros meios de prova ou mesmo em meros indícios, a verossimilhança daquilo que foi relatado será maior. Não se mostra imperioso que a prova corroboradora do depoimento infantil diga respeito ao mérito da demanda judicial e seja forte, mas apenas que torne crível o depoimento infantil, de modo que uma prova periférica muitas vezes se mostra útil para essa finalidade.

Indica, ainda, a doutrina que o conteúdo do depoimento da criança deve ser analisado sob a perspectiva da emissão de detalhes oportunistas a favor do declarante. A criança, ao emitir uma opinião no processo judicial a favor de si mesma ou de alguma outra pessoa, declara a versão mais recente por ela 
vivenciada, dada a especial intensidade e transitoriedade de suas emoções e pelo alto ou baixo grau cognitivo. É por isso que essa opinião subjetiva da criança não deve ser considerada, salvo se acompanhada de outros elementos de prova ${ }^{19}$.

Somente a comunhão de todos esses elementos de prova pode levar a uma valoração da prova adequada, que respeite a condição especial da criança como pessoa em desenvolvimento e dê efetiva aplicação ao princípio da proteção integral.

No entanto, não basta o exame da prova oral infantil de acordo com os parâmetros indicados. É essencial que se verifique a norma de direito material invocada nos autos para se analisar o modelo de constatação aplicável. Isso porque, nas causas cíveis, o critério de valoração da prova pode ser o da preponderância da prova ou o da prova clara e convincente. A primeira requer uma mera preponderância do grau da prova em um determinado sentido para que o julgador já possa decidir (TARUFFO, 2014). A segunda, de maneira mais destacada e apenas para as situações de direito material mais sensíveis que envolvam direitos da personalidade, busca maior intensidade probatória para que a demanda seja julgada (SOUSA, 2013).

Essa é a razão pela qual a prova oral infantil deve ser valorada diferentemente a depender da pretensão das partes. Em uma ação de disputa judicial de guarda, em que é feita a audição da criança interessada, esse depoimento deve ser examinado sob os prismas da coerência e da contextualização da prova, sempre considerando antecipadamente os modelos e métodos de inquirição. Logo, havendo preponderância da prova para se deferir a guarda em favor de uma das partes, o juiz pode assim decidir sem que se ofenda a lógica do discurso justificador.

De outro lado, em situação de destituição do poder familiar ou parental, o depoimento da criança há de ser contextualizado com as demais provas dos autos, de modo que o julgamento procedente da demanda pressupõe a existência de prova de forte intensidade no sentido do não respeito do dever de proteção, guarda, sustento e educação. Como se trata de direito sensível, a destituição do poder

\footnotetext{
${ }^{19}$ Interessante exemplo é dado por Jordi Nieva Fenoll (2012), ao dizer que constitui um grande erro ouvir somente a criança interessada na causa para dizer com qual dos pais ela quer viver porque a resposta pode depender simplesmente da última relação de afeto que a criança manteve.
} 
familiar ou parental se apresenta como uma mudança drástica na vida dos pais, de modo que somente uma prova de intensidade fortalecida é capaz de retirar deles esse direito.

\section{O DEPOIMENTO DA CRIANÇA COMO FONTE ÚNICA DE PROVA}

Caso de difícil solução se dá quando a prova oral infantil é a única produzida nos autos. Nessa peculiar situação, fica prejudicada a contextualização do depoimento infantil com os demais elementos de prova.

Ficou defendido anteriormente que, a depender do direito material em disputa na demanda judicial, o módulo de constatação vai variar. Em alguns casos, denominados comuns, basta a prova preponderante em um dos sentidos da pretensão para o julgamento favorável da causa. Em outros, denominados sensíveis, a intensidade da prova para a procedência da ação deve ser tamanha que os elementos de prova em sentido contrário devem ser frágeis que não possam alterar a lógica da decisão judicial.

Nessa esteira, tem-se que o depoimento infantil isoladamente analisado no processo judicial se mostra de difícil solução, na medida em que não basta invocar o direito material de fundo para determinar o módulo de constatação se o depoimento em si não guarda coerência. O depoimento infantil que, isoladamente analisado, trouxer profundas e variadas contradições e que apresenta falhas quanto ao fato principal acaba por ficar fragilizado para fundamentar a procedência de uma ação judicial independentemente do direito material invocado.

Não se espera um depoimento infantil perfeito, que discorra cronológica e detalhadamente os fatos ocorridos. Ao contrário, apresenta-se bastante razoável a existência de falhas e lapsos de esquecimento, desde que não existam contradições pontuais sobre os fatos principais da demanda. A melhor análise dessa situação se dá apenas com a entrevista na modalidade narrativa, ou seja, com um método de inquirição que permita ao juiz descobrir se o relato da criança é falso por ter sido influenciado por algum elemento externo voluntário ou não. Esse método permite a 
identificação daquelas narrativas decoradas que favorecem uma das partes, bem como auxilia os examinadores no momento da narrativa de falsas memórias.

No método tradicional de prestação de depoimentos, em que as perguntas são feitas de maneira interrogativa e sugestiva, a verificação de situações de falsidade voluntária ou não é difícil. Essa espécie de método não valoriza a narrativa livre da criança e introduz no depoimento elementos fáticos que poderiam não ser recordados pela criança.

Assim, quando se trata de prova oral infantil, dentro do módulo de constatação da preponderância da prova (TARUFFO, 2014), esse meio de prova pode se mostrar suficiente para o julgamento da causa, dado que basta a preponderância em um dos sentidos para justificar a racionalidade da decisão.

De outro ponto, caso adotado o método narrativo de prestação de depoimento e verificado que o depoimento infantil é a única prova dos autos e que foi prestado de maneira coerente, sem contradições graves, parece dificultoso admiti-lo como prova suficiente para o julgamento de uma causa que reivindique o modelo de constatação da prova clara e convincente. Isso porque a prova testemunhal, em si, sempre questionável, dada a própria essência social do ser humano de trabalhar com verdades e mentiras e pelo próprio grau cognitivo da criança não inteiramente desenvolvido, não permite uma prova com a intensidade necessária para a procedência da ação. A comparação do testemunho da criança com o homem médio permite concluir que o grau de desenvolvimento cognitivo insuficiente pode afetar a recordação dos fatos, de modo que a prova não terá o grau de certeza suficiente para julgamento da demanda.

\section{CONSIDERAÇÕES FINAIS}

À guisa de conclusão, é possível afirmar que o direito processual brasileiro atribui tratamento diferenciado ao depoimento especial de crianças e adolescentes, já que, enquanto no processo penal, qualquer pessoa pode ser testemunha de um fato, inclusive crianças e adolescentes, no processo civil, em regra, os menores de 16 anos são considerados incapazes e, portanto, impedidos de prestarem 
depoimento. A Lei n. 13.341/17 inovou o sistema processual ao trazer um sistema próprio de tomada de depoimentos de crianças e de adolescentes, preocupada com a preservação da sua saúde física e mental, não fazendo qualquer distinção entre o âmbito cível ou penal.

Embora os ordenamentos jurídicos brasileiro e português ainda não disponham expressamente acerca dos métodos racionais de controle das decisões judiciais, verifica-se que a jurisprudência começa a dar os seus primeiros passos. Exige-se do magistrado a devida fundamentação da decisão como mecanismo de controle da atividade jurisdicional. É por meio da fundamentação que o magistrado analisará a credibilidade de um depoimento, inclusive no tocante a crianças e adolescentes. Caberá uma criteriosa análise do julgador acerca do depoimento especial infantil em relação a quatro critérios de modo a decidir se aceita ou se rechaça a prova: a) finalidade do processo mnésico; b) apreciação da imparcialidade; c) forma de prestação do depoimento; d) conteúdo do depoimento. Ademais, existem instrumentos disponíveis para detectar a veracidade ou a falsidade dos depoimentos, tais como o Statement Validity Assessment (Avaliação da Validade de Depoimentos) e o Reality Monitoring (Monitoramento da Realidade).

Para a escorreita valoração da prova, o magistrado também deverá analisar os modelos e os métodos de inquirição da criança e do adolescente, devendo considerar todos os fatores internos ou externos que possam interferir na credibilidade do depoimento especial. Para isso, é fundamental criar condições que possam reduzir a carga emocional da criança e do adolescente, por meio de um adequado rapport, estabelecimento de modelos protetivos de tomada de depoimento, tais como o CCTV e a Câmara de Gesell, emprego de técnicas adequadas de inquirição, além da exclusão de contato com as partes e de perguntas vexatórias ou constrangedoras.

Além dos modelos e métodos de inquirição, torna-se fundamental observar o estágio de desenvolvimento cognitivo da criança, que se mostra mais útil ao processo, dada a sua maturidade, a partir dos sete ou oito anos de idade. Ademais, é fundamental contextualizar o seu depoimento com as demais provas produzidas nos autos. 
Também é fundamental analisar o modelo de constatação aplicável na valoração da prova. No processo civil, há dois modelos: I) o modelo da preponderância da prova, em que o magistrado opta por uma das provas produzidas nos autos, ideal para as ações cujo interesse em litígio é meramente patrimonial; II) o modelo da prova clara e convincente, aplicável às questões de maior relevância, em que o magistrado exigirá uma prova mais robusta, como sói ocorrer nas questões existenciais. $O$ modelo de constatação ganha maior relevância sobretudo nos casos em que o depoimento da criança é a única fonte de prova, devendo o magistrado, fundamentadamente, decidir se acolhe ou afasta o depoimento infantil.

Por fim, conclui-se que a valoração da prova não é uma tarefa fácil. Exige do magistrado uma redobrada atenção aos detalhes, aos métodos, às técnicas de inquirição e às demais provas dos autos para uma análise conjunta. Essa tarefa se torna ainda mais difícil diante do depoimento de crianças e adolescentes, dada a sua condição peculiar de pessoa em desenvolvimento. A certeza é que não se trata de uma tarefa isolada do Direito, havendo a necessidade de um diálogo constante com outras áreas do conhecimento, como a Psicologia, em um verdadeiro trabalho interdisciplinar que se encontra em seu nascedouro.

\section{REFERÊNCIAS}

BALBINOTTI, Cláudia. A violência sexual infantil intrafamiliar: a revitimização da criança e do adolescente vítimas de abuso. Direito \& Justiça. v. $35, n^{\circ} 1$, p. $05-21$, jan./jun., 2009. Disponível em: http://www. http://revistaseletronicas.pucrs.br. Acesso em: 17 maio 2020.

BATTISTELLI, Luigi. A mentira nos tribunais: estudos de psicologia e psicopatologia judiciária. Coimbra: Coimbra Editora, 1963.

BRASIL. Lei $\mathrm{n}^{\circ}$. 13.105, de 16 de março de 2015. Institui o Código de Processo Civil. Brasília, DF: Presidência da República, [2015]. Disponível em: http://www.planalto.gov.br/ccivil_03/_ato2015-2018/2015/lei//13105.htm. Acesso em: 17 maio 2020.

BRASIL. Lei 13.431, de 04 de abril de 2017. Estabelece o sistema de garantia de direitos da criança e do adolescente vítima ou testemunha de violência e altera a Lei no 8.069, de 13 de julho de 1990 (Estatuto da Criança e do Adolescente). Brasília, DF: Presidência da República, [2017]. Disponível em: 
http://www.planalto.gov.br/ccivil_03/_ato2015-2018/2017/lei//13431.htm. Acesso em: 17 maio 2020.

BRASIL. Superior Tribunal de Justiça. Recurso Especial 363548/SC. Processual Penal. Recurso Especial. Delito de Falsum. Reexame e revaloração da prova. Silêncio do réu. Livre convencimento e convicção íntima. Relator: Min. Felix Fischer, 02 de maio de 2002. Disponível em:

https://stj.jusbrasil.com.br/jurisprudencia/290364/recurso-especial-resp-363548. Acesso em: 24 ago. 2021.

BRASIL. Tribunal de Justiça do Rio Grande do Sul. Apelação 70038651477. Relator: Desembargador Umberto Guaspari Sudrack, 27 set. 2012.

CABRITA, Helena. A Fundamentação de facto e de direito da decisão cível. Coimbra: Coimbra Editora, 2015.

CALHEIROS, Maria Clara. Para uma teoria da prova. Coimbra: Coimbra Editora, 2015.

CÉZAR, José Antônio Daltoé. Depoimento sem dano: uma alternativa para inquirir crianças e adolescentes nos processos judiciais. Porto Alegre: Livraria do Advogado, 2007.

FENOLL, Jordi Nieva. La declaración de niños en calidad de partes o testigos. Justicia. Revista de Derecho Procesal. Madrid: Bosch, 2012, n. 1, p. 121-141.

FURNISS, Tilman. Abuso Sexual da Criança: uma abordagem multidisciplinar. Porto Alegre: Artes Médicas, 1993.

HERMIDA, Ágata María Sanz. La declaración de los menores víctimas y/o testigos de delitos: Derecho de defensa, protección del interés del menor y eficacia de la justicia penal. In: DEU, Teresa Armenta; VALL-LLOVERA, Susana Oromí. La víctima menor de edad. Madrid: Colex, 2010, p. 111-133.

JARAMILLO, Lina Marcela Estrada. La Cámara Gesell: una herramienta para la entrevista de niños y niñas adolescentes en los procesos de familia. Revista de Direito Internacional e Direitos Humanos da UFRJ, Rio de Janeiro, v. 2, n. 1, 2019.

MALATESTA, Nicola Flamarino dei. A Lógica das provas em matéria criminal. Tradução Paolo Capitanio. 6 ed. Campinas, SP: Bookseller, 2005.

MANZANERO, Antonio L. Memoria de testigos: obtención y valoración de la prueba testifical. Madrid: Ediciones Piramides, 2010.

NUNES, Carlos Casimiro. O abuso sexual de crianças e jovens: a intervenção judicial à luz dos processos psicológicos envolvidos. Revista do Instituto Superior de Polícia Judiciária e Ciências Criminais. Coimbra: Coimbra Editora, 2005, III Série, $n^{\circ} 5$, jan./jun., p. 261-305. 
PASQUALINI, Juliana Campregher. A perspectiva histórico-dialética da periodização do desenvolvimento infantil. Disponível em: http://www.scielo.br/pdf/pe/v14n1/a05v14n1. Acesso em: 17 maio 2020.

PESSOA, Alberto. A prova testemunhal (Estudo de Psicologia Judiciária). Sorocaba: Minelli, 2006.

PIAGET, Jean. Seis Estudos de Psicologia. Rio de Janeiro: Editora Forense, 1971.

POIARES, Carlos Alberto. Psicologia do testemunho: contribuição para aproximação da verdade judicial à verdade. Revista Jurídica da Universidade Portucalense Infante D. Henrique. Porto: Universidade Portucalense, 2004, n. 12, p. 77-94.

PORTUGAL. Lei n. 41, de 26 de junho de 2013. Institui o Código de Processo Civil de Portugal. Lisboa: Ministério Público. Disponível em:

http://www.pgdlisboa.pt/leis/lei_mostra_articulado.php?nid=1959\&tabela=leis.

Acesso em: 17 maio 2020.

PORTUGAL. Tribunal da Relação de Coimbra. Processo 1994, de 06.03.2012, Relator Teles Pereira.

PORTUGAL. Tribunal da Relação de Évora. Processo 5901, de 06.12.2011, Relator António João Latas.

PORTUGAL. Tribunal da Relação do Porto. Apelação 9951197, de 24.01.2000, Relator Pinto Ferreira.

PORTUGAL. Tribunal da Relação do Porto. Apelação 0820528, de 01.04.2008, Relator Guerra Banha.

RASSIER, F. De la valeur du témoignage des enfants. Paris: G. Masson, 1892.

SADOCK, Benjamin James; SADOCK, Virginia Alcott. Compêndio de psiquiatria: ciências do comportamento e psiquiatria clínica. 9. ed. Porto Alegre: Artmed, 2007.

SANTOS, Benedito Rodrigues dos, et al. Cartografia nacional das experiências alternativas de tomada de depoimento especial de crianças e adolescentes em processos judiciais no Brasil: o estado da arte. São Paulo: Childhood Brasil; Editora da Universidade Católica de Brasília, 2013.

SANTOS, Moacyr Amaral. Prova judiciária no cível e comercial. v. 3. 4. ed. São Paulo: Max Limonad, 1972.

SOUSA, Luís Filipe Pires de. Prova testemunhal. Coimbra: Almedina, 2013.

STEIN, Lilian Milnitsky; PERGHER, Giovanni Kuckartz; FEIX, Leandro da Fonte. Desafios da oitiva de crianças e adolescentes: técnica de entrevista investigativa. Brasília: Secretaria Especial dos Direitos Humanos da Presidência da República, 2009. 
TARUFFO, Michele. A prova. Tradução João Gabriel Couto. São Paulo: Marcial Pons, 2014.

TERRA, Márcia Regina. O desenvolvimento humano na teoria de Piaget.

Disponível em: http://www.unicamp.br/iel/site/alunos/publicacoes/textos/d00005.htm. Acesso em: 17 maio 2020.

TRINDADE, Jorge. Manual de psicologia jurídica para operadores do Direito. 7 ed. Porto Alegre: Livraria do Advogado, 2014.

WELTER, Carmen Lisbôa Weingartner; FEIX, Leandro da Fonte. Falsas memórias, sugestionabilidade e testemunho infantil. In: STEIN, Lilian Milnitsky (org.). Falsas memórias: fundamentos científicos e suas aplicações clínicas e jurídicas. Porto Alegre: Artmed, 2010. 